\title{
Validation and psychometric properties of the Maltese version of the Duke Anticoagulation Satisfaction Scale (DASS)
}

This article was published in the following Dove Press journal: Psychology Research and Behavior Management

\author{
Nicoletta Riva' \\ Christian Borg Xuereb ${ }^{2}$ \\ Walter Ageno ${ }^{3}$ \\ Michael Makris ${ }^{4}$ \\ Alex Gatt' \\ 'Department of Pathology, Faculty of \\ Medicine and Surgery, University of \\ Malta, Msida, Malta; ${ }^{2}$ Department of \\ Gerontology and Dementia Studies, \\ Faculty for Social Wellbeing, University of \\ Malta, Msida, Malta; ${ }^{3}$ Department of \\ Medicine and Surgery, University of \\ Insubria, Varese, Italy; ${ }^{4}$ Sheffield \\ Haemophilia and Thrombosis Centre, \\ University of Sheffield, Sheffield, UK
}

Purpose: Assessing treatment satisfaction can guide specific interventions to improve anticoagulation adherence and reduce adverse outcomes. We aimed to assess the psychometric properties (reliability and validity) of the Maltese translation of the Duke Anticoagulation Satisfaction Scale (DASS).

Patients and methods: The DASS explores three dimensions (limitations, hassles/burdens, psychological impact). The translation process included forward and backward translations. Reliability was evaluated through internal consistency and reproducibility. Validity was evaluated through floor/ceiling effect, convergent/discriminant validity, construct validity, and known-group validity.

Results: The Maltese version of the DASS, administered to 174 patients on warfarin for different clinical indications, showed good reliability (Cronbach's alpha 0.87 ; intraclass correlation coefficient for test-retest 0.73 ). Floor effect was identified mainly in the limitations and hassles/burdens subscales. Significant positive correlations were found between the DASS total score and its subscales (limitations 0.80 , hassles/burdens 0.85 , psychological impact 0.68 ). Female sex, shorter warfarin treatment duration ( $\leq 5$ years), previous hospitalization and history of bleeding were associated with lower satisfaction.

Conclusion: Psychometric properties of the Maltese DASS were comparable to the original English version. The Maltese version of the DASS is a valid and reliable instrument that can be used by health care professionals to assess the level of satisfaction of Maltese-speaking anticoagulated patients.

Keywords: atrial fibrillation, psychometrics, quality of life, surveys and questionnaires, venous thromboembolism, warfarin

\section{Introduction}

As anticoagulant therapy is a chronic treatment for most clinical indications, it can affect patients' quality of life and satisfaction. ${ }^{1-3}$ Vitamin $\mathrm{K}$ antagonists (VKA) are one of the oral anticoagulant medications currently available for the treatment and secondary prevention of venous thromboembolism (VTE) and for stroke prevention in patients with atrial fibrillation (AF). ${ }^{4}$ VKAs require routine laboratory monitoring in order to maintain the international normalized ratio (INR) within the therapeutic target range and have several food/drug restrictions, therefore contributing to the burden of these medications. ${ }^{2,4}$

Health-related quality of life (QoL) is an important aspect in the decision-making process and can be measured through the use of generic scales and condition-specific
Correspondence: Nicoletta Riva

Department of Pathology, Faculty of

Medicine and Surgery, University of Malta,

Msida, MSD 2080, Malta

Tel +35625452518

Fax +35625450000

Email nico.riva@hotmail.it 
scales. Generic scales, e.g., the 36 -item Short Form ${ }^{5}$ or the 12-item Short Form, ${ }^{6}$ can be applied to patients with different conditions, such as rheumatological, orthopedic and hematological diseases. ${ }^{7-9}$ Specific scales measure aspects of QoL that are related to a particular condition, for instance, the Duke Anticoagulation Satisfaction Scale (DASS) and the Perception of Anticoagulant Treatment Questionnaire (PACT-Q) measure the QoL of anticoagulated patients. ${ }^{10,11}$ Understanding the degree of satisfaction associated with the anticoagulant treatment allows for specific interventions to focus on increasing the anticoagulation adherence and reduce adverse clinical outcomes. However, there was no such scales assessing the satisfaction of anticoagulated patients that had been validated in the Maltese language.

We chose to translate the DASS and the PACT-Q because they have been used in several studies enrolling patients with various clinical indications to the anticoagulant treatment. ${ }^{10,12-19}$ The aim of this study was to assess the psychometric properties (reliability and validity) of the Maltese version of the DASS. The psychometric properties of the Maltese version of the PACT-Q have been reported in a separate paper. ${ }^{20}$

\section{Materials and methods The DASS}

The DASS explores three dimensions: limitations (9 items), hassles and burdens (8 items) and psychological impact (5 positive items and 3 negative items). ${ }^{10}$ Therefore, the DASS has 25 items, each with 7 possible responses (not at all, a little, somewhat, moderately, quite a bit, a lot, and very much). Six items require reverse-coding prior to analysis. The final score can range from 25 to 175 , with lower scores representing greater satisfaction and less hassles and burdens. $^{10}$

Permission to translate and use the DASS was obtained from the corresponding author of the original DASS paper. ${ }^{10}$ According to published guidelines, ${ }^{21,22}$ different people, all bilingual in English and Maltese (a professional translator, a health psychologist, and a speech and language pathologist), were involved in the translations of the DASS, with two forward translations from English to Maltese and a backward translation from Maltese to English. For the pilot testing of the Maltese version of the DASS, the questionnaire was completed and discussed with 5 patients on long-term oral anticoagulant treatment (not included in this analysis).

\section{Study population}

The Maltese version of the DASS was completed by 174 patients on warfarin treatment for different clinical indications, enrolled from the Anticoagulation Clinics at 5 Health Centres (Cospicua, Floriana, Mosta, Qormi, Rabat) and at Mater Dei Hospital (Msida) in Malta. INR testing at the Health Centres is performed using point-of-care devices, while at Mater Dei Hospital is performed using traditional venepuncture. In both settings, warfarin dose adjustment is decided by the attending physicians. Patients with cognitive impairment, dementia or major psychiatric disorders (such as schizophrenia) were excluded.

The questionnaires were distributed by two authors (NR, CBX) between July 2017 and February 2018 and patients were also asked to fill in a form on sociodemographic data (age, sex, living situation, level of education, working status, and selfreported history of any bleeding). Questionnaires were identified using a code, to ensure anonymity. The researchers had the list with the correspondence between the code and the demographic details, which was used to contact the patients only in case of missing values. Therefore, there were no missing answers in our cohort. From a review of clinical notes, we also collected information on clinical indication and duration of the anticoagulant treatment, INR on the day of enrollment, INR results and any hospitalization in the previous year.

For the purpose of this validation study, we also considered 157 patients who completed the English version of the DASS, enrolled from the same Anticoagulation Clinics during the same time frame. Malta is a bilingual country, where Maltese is the national language and English is considered a co-official language. ${ }^{23}$ The choice of whether to complete the Maltese or the English version of the DASS was left at the discretion of each patient.

A randomly chosen sample of 40 patients was retested after 7-14 days: 20 patients who initially completed the Maltese version and 20 patients who initially completed the English version. Half of each group was retested in the same language (to estimate the intra-language correlation), while the other half was retested in the other language (to estimate the cross-language correlation).

This study was approved by the University of Malta Research and Ethics Committee (Ref No 07/2016) and all patients signed an informed consent form before inclusion.

\section{Statistical analysis}

Continuous variables were expressed as mean \pm SD and compared using the Student's independent samples $t$-test; 
categorical variables were expressed as counts and percentages and compared using the Chi-square or the Fisher's exact tests, as appropriate.

For the calculation of the DASS score, six items (3h, $4 \mathrm{a}$, $4 \mathrm{~b}, 4 \mathrm{f}, 4 \mathrm{~h}$ and $4 \mathrm{j}$ ) were reverse-coded, as reported in the original publication. $^{10}$

Reliability of the Maltese version of the DASS was evaluated through internal consistency and reproducibility. ${ }^{24}$ The internal consistency (correlation between different items on the same scale or subscale) was assessed using the Cronbach's alpha coefficient, with a value $\geq 0.70$ considered acceptable. $^{25}$

Reproducibility was assessed in the subgroup of patients who participated in the test-retest in the same language and the intraclass correlation coefficients (ICC) were calculated (intra-language correlation for the Maltese-Maltese test-retest and the English-English test-retest). Commonly cited cut-off for ICC considers acceptable values between 0.60 and $0.74 .^{26}$ We evaluated the cross-language test-retest correlation in those patients who participated in the test-retest in the other language. We calculated the raw cross-language correlation and the adjusted cross-language correlation (adjusted for score unreliability by dividing the raw cross-language test-retest correlation by the square-root of the product of the Maltese-Maltese and English-English test-retest intra-language correlation). ${ }^{27,28}$ For the cross-language correlation, the English-Maltese and Maltese-English test-retest groups were pooled together, as previously done. ${ }^{28}$

Validity of the Maltese version of the DASS was evaluated through floor and ceiling effect, convergent and discriminant validity, construct validity, and knowngroup validity. Floor effect occurs when a significant proportion of respondents $(>15 \%)$ achieves the lowest score; vice versa, ceiling effect occurs when a significant proportion of respondents $(>15 \%)$ achieves the highest score, meaning that there is more variance that the questionnaire is able to capture (limited content validity). ${ }^{29}$

Convergent and discriminant validity was assessed through factor analysis. An exploratory factor analysis with varimax rotation was performed to examine the structure of the DASS. In the confirmatory factor analysis the following parameters were calculated: root mean square error of approximation (RMSEA), where values $\leq 0.05$ correspond to "good fit," and values $\leq 0.08$ correspond to "acceptable fit"; standardized root mean squared residual (SRMR), where values $\leq 0.05$ correspond to "good fit," and values $\leq 0.10$ correspond to "acceptable fit"; goodness-of- fit index (GFI), adjusted goodness-of-fit index (AGFI) and comparative fit index (CFI), where values $\geq 0.90$ are considered "acceptable fit.",30

Construct validity was evaluated by assessing the Pearson's correlation between different subscales and between each subscale and the overall DASS (scale-subscale validity). $^{31}$

Known-group validity was evaluated by assessing the correlation (Pearson's or point-biserial correlation as appropriate) between the overall DASS score and the following covariates, some of which have been previously shown to correlate with patients' satisfaction ${ }^{10,12,13,32,33}$ : increasing age; male sex; living alone; level of education primary school only; full-time or part-time paid employment; AF as clinical indication to anticoagulant treatment; warfarin treatment duration $>5$ years; INR in range at enrollment; high time within therapeutic range (TTR $\geq 70 \%$, calculated according to the Rosendaal method ${ }^{34}$ ) in the previous 12 months; any hospitalization in the previous 12 months; self-reported history of any bleeding on warfarin.

We planned a sample size of at least 150 patients, given that published recommendations considered adequate a sample size of at least 50 patients $^{29}$ and that previous validation studies enrolled approximately 100 patients. $^{35,36}$

Statistical analysis was performed using the statistical software STATA SE v.12 (StataCorp LP, College Station, TX, USA) and SAS v. 9.4 (SAS Institute Inc, Cary, NC, USA), with two-tailed $P<0.05$ considered statistically significant.

\section{Results}

\section{Study population}

Baseline characteristics of the enrolled patients, including sociodemographic details, are reported in Table 1. The comparison between patients who completed the Maltese and the English version of the DASS showed some differences: there was a predominance of female $(P=0.01)$ and primary school level of education $(P<0.001)$ among those subjects who completed the Maltese version of the DASS; while full- or part-time employment $(P<0.001)$ and heart valve replacement as indication to warfarin $(P=0.02)$ were more common among those subjects who completed the English version of the DASS. While the overall DASS score was similar in the two cohorts, patients who completed the Maltese version obtained higher scores in the psychological impact subscale (mean \pm SD 23.4 \pm 6.2 for the Maltese version vs 21.3 \pm 7.4 for the English version, $P=0.006$ ), corresponding to lower anticoagulation satisfaction. 
Table I Baseline characteristics of the study population

\begin{tabular}{|c|c|c|c|}
\hline & $\begin{array}{l}\text { Patients who completed the } \\
\text { Maltese questionnaire }(n=\mid 74)\end{array}$ & $\begin{array}{l}\text { Patients who completed the } \\
\text { English questionnaire }(n=\mid 57)\end{array}$ & $P$-value \\
\hline Age (years), mean (SD) & $70(10.1)$ & $69.8(10.2)$ & 0.87 \\
\hline Females, n (\%) & $92(52.9)$ & $61(38.9)$ & 0.01 \\
\hline \multicolumn{3}{|l|}{ Living situation, $\mathrm{n}(\%)$} & \multirow[t]{4}{*}{0.82} \\
\hline Living with family members & $138(79.3)$ & $124(79.0)$ & \\
\hline Living alone & $31(17.8)$ & $30(19.1)$ & \\
\hline Other & $5(2.9)$ & $3(1.9)$ & \\
\hline \multicolumn{3}{|l|}{ Level of education, n (\%) } & \multirow[t]{4}{*}{$<0.001$} \\
\hline Primary school & $108(62.1)$ & $36(22.9)$ & \\
\hline Secondary school & $48(27.6)$ & $67(42.7)$ & \\
\hline College or above & $18(10.3)$ & $54(34.4)$ & \\
\hline \multicolumn{3}{|l|}{ Employment status, n (\%) } & \multirow[t]{4}{*}{$<0.001$} \\
\hline Full-time or part-time paid employment & $18(10.3)$ & $25(15.9)$ & \\
\hline Retired/pension & $103(59.2)$ & $114(72.6)$ & \\
\hline Other (homemaker/housewife, unemployed) & $53(30.5)$ & $18(11.5)$ & \\
\hline \multicolumn{4}{|l|}{ Clinical indications to warfarin, $\mathrm{n}(\%)^{\mathrm{a}}$} \\
\hline Atrial fibrillation & $122(70.1)$ & $97(61.8)$ & 0.11 \\
\hline Venous thromboembolism & $30(17.2)$ & $23(14.7)$ & 0.52 \\
\hline Heart valve replacement & $25(14.4)$ & $38(24.2)$ & 0.02 \\
\hline Other & $25(14.4)$ & $9(5.7)$ & 0.32 \\
\hline \multicolumn{3}{|l|}{ Warfarin treatment duration, $\mathrm{n}(\%)$} & \multirow[t]{3}{*}{0.15} \\
\hline$\leq 5$ years & $98(56.3)$ & $76(48.4)$ & \\
\hline$>5$ years & $76(43.7)$ & $81(51.6)$ & \\
\hline \multicolumn{3}{|l|}{ INR at enrollment, n (\%) } & \multirow[t]{3}{*}{0.31} \\
\hline In range & $99(56.9)$ & $98(62.4)$ & \\
\hline Other (above or below range) & $75(43.1)$ & $59(37.6)$ & \\
\hline High TTR $(\geq 70 \%)$ in the previous year, $n(\%)^{b}$ & $96(56.5)$ & $89(59.7)$ & 0.56 \\
\hline Any hospitalisation in the previous year, $\mathrm{n}(\%)^{\mathrm{b}}$ & $86(50.6)$ & $77(5 \mid .7)$ & 0.85 \\
\hline Self-reported history of any bleeding, $n(\%)$ & $63(36.2)$ & $50(31.9)$ & 0.40 \\
\hline \multicolumn{3}{|l|}{ Site of enrollment, n (\%) } & \multirow[t]{3}{*}{0.96} \\
\hline Health centers & $86(49.4)$ & $78(49.7)$ & \\
\hline Mater Dei Hospital & $88(50.6)$ & $79(50.3)$ & \\
\hline \multicolumn{4}{|l|}{ DASS results, mean (SD) } \\
\hline Overall score & $56.7(18.5)$ & $53.6(16.9)$ & 0.18 \\
\hline Limitations subscale & I7.I (9.4) & $17.0(8.0)$ & 0.92 \\
\hline Hassles/burdens subscale & $16.2(8.0)$ & $15.3(6.7)$ & 0.27 \\
\hline Psychological impact subscale & $23.4(6.2)$ & $21.3(7.4)$ & 0.006 \\
\hline
\end{tabular}

Notes: a More than one option is possible. ${ }^{b}$ Data available only in 170 patients who completed the Maltese version and 149 patients who completed the English version. Abbreviations: INR, international normalized ratio; TTR, time within therapeutic range; DASS, Duke Anticoagulation Satisfaction Scale. 


\section{Internal consistency}

The internal consistency of the Maltese translation of the DASS was good with the following Cronbach's alpha coefficients: 0.87 for the overall DASS total score; 0.86 for the limitations subscale ( 9 items); 0.84 for the hassles and burdens subscale ( 8 items); 0.65 for the positive ( 5 items) and 0.64 for the negative ( 3 items) psychological impact subscales. When the 8 items of the psychological impact subscale were considered together, Cronbach's alpha was 0.57.

The English version of the DASS also shows good internal consistency in our cohort: overall DASS Cronbach's alpha 0.85 ; limitations subscale 0.82 ; hassles and burdens subscale 0.79 ; positive psychological impact 0.79 ; negative psychological impact 0.56 ; overall psychological impact 0.71 .

Details of the internal consistency analysis are reported in Table 2. No significant increase or decrease of the Cronbach's alpha coefficients was observed when each question was deleted.

\section{Reproducibility}

ICC for the intra-language correlation was very good, being 0.73 for the DASS total score in the MalteseMaltese test-retest and 0.85 in the English-English testretest. Further details of the intra-language correlation, including DASS subscales, are reported in Table S1.

ICC for the cross-language correlation for the DASS total score was 0.31 and the adjusted cross-language correlation was 0.39 . When analyzed separately, ICC for the English-Maltese test-retest was 0.59, while ICC for the Maltese-English test-retest was 0.

\section{Floor and ceiling effect}

When we analyzed the response distribution for each item of the Maltese translation of the DASS, a significant floor effect was identified, mainly in questions pertaining to the limitations and hassles/burdens subscales (Table 3). Except for one question, no significant ceiling effect was detected. However, a significant floor effect was observed also in the English version of the DASS in our study (Table S2) and in the original publication of the DASS. ${ }^{10}$

We subsequently analyzed the results of the overall DASS score and each subscale. In the Maltese version floor effect was $0 \%$ for the overall DASS, $15.5 \%$ for limitations, $3.5 \%$ for hassles/burdens, and $0 \%$ for psychological impact $(1.2 \%$ for positive and $12.1 \%$ for negative psychological impact). In the English version floor effect was $0 \%$ for the overall DASS, $12.1 \%$ for limitations, $14.7 \%$ for hassles/burdens, and $1.9 \%$ for psychological impact (6.4\% for positive and $14.0 \%$ for negative psychological impact). Ceiling effect was $0 \%$ for all subscales in both languages.

\section{Factor analysis}

Results of the confirmatory factor analysis were unsatisfactory. For the Maltese version of the DASS, RMSEA and SRMR (both 0.13 ) were slightly above the acceptable value ( $\leq 0.08$ and $\leq 0.10$, respectively); whereas GFI ( 0.64$)$, AGFI (0.57) and CFI (0.67) were all below the adequate fit level $(\geq 0.90)$. However, we obtained similar unsatisfactory results for the English version of the DASS in our study cohort: RMSEA 0.10, SRMR 0.14, GFI 0.66, AGFI 0.65, CFI 0.63. Detailed results of the factor analysis and the rotated factor pattern, in comparison to previously published studies, ${ }^{10,13}$ is reported in Table 4.

\section{Correlation scale-subscales}

We found a statistically significant positive correlation between the DASS total score and its main subscales. For the Maltese version correlation coefficients were 0.80 for limitations, 0.85 for hassles and burdens, and 0.68 for psychological impact. For the English version correlation coefficients were $0.74,0.82$, and 0.74 , respectively. Details of the correlation between each subscale are reported in Table S3.

\section{Known-group validity}

The Maltese version of the DASS showed a significant positive correlation with previous hospitalization and previous bleeding events, a significant negative correlation with longer anticoagulant treatment duration, and a borderline negative correlation with male sex. These findings suggest that female sex, shorter treatment duration ( $\leq 5$ years), previous hospitalization and history of bleeding are associated with lower satisfaction.

The English version of the DASS showed a significant negative correlation with increasing age and male sex, and a significant positive correlation with paid-employment status and previous bleeding. These findings suggest that young age, female sex, full- or part-time paid employment and history of bleeding are associated with lower satisfaction.

However, for all the significant sociodemographic and clinical characteristics the correlation with the DASS total score was in the same direction for both languages, although sometimes lacking of statistical significance (Table 5). 
Table 2 Internal consistency of the Maltese and English versions of the DASS in our study cohort

\begin{tabular}{|c|c|c|c|c|c|c|c|}
\hline \multirow[t]{2}{*}{ DASS } & \multirow[t]{2}{*}{ Item } & \multicolumn{3}{|c|}{ Maltese version } & \multicolumn{3}{|c|}{ English version } \\
\hline & & $\begin{array}{l}\text { Cronbach's } \\
\text { alpha } \\
\text { coefficient }\end{array}$ & $\begin{array}{l}\text { Item-total } \\
\text { correlation }\end{array}$ & $\begin{array}{l}\text { Cronbach's } \\
\text { alpha if item } \\
\text { deleted }\end{array}$ & $\begin{array}{l}\text { Cronbach's } \\
\text { alpha } \\
\text { coefficient }\end{array}$ & $\begin{array}{l}\text { Item-total } \\
\text { correlation }\end{array}$ & $\begin{array}{l}\text { Cronbach's } \\
\text { alpha if item } \\
\text { deleted }\end{array}$ \\
\hline $\begin{array}{l}\text { DASS score } \\
\text { (overall) }\end{array}$ & & 0.87 & & & 0.85 & & \\
\hline \multirow[t]{2}{*}{ Limitations subscale } & & 0.86 & & & 0.82 & & \\
\hline & $\begin{array}{l}\mathrm{Ia} \\
\mathrm{Ib} \\
\mathrm{Ic} \\
\mathrm{Id} \\
\mathrm{le} \\
2 \mathrm{a} \\
2 \mathrm{~b} \\
2 \mathrm{c} \\
2 \mathrm{~d}\end{array}$ & & $\begin{array}{l}0.60 \\
0.63 \\
0.72 \\
0.70 \\
0.72 \\
0.46 \\
0.31 \\
0.60 \\
0.70\end{array}$ & $\begin{array}{l}0.85 \\
0.85 \\
0.84 \\
0.84 \\
0.84 \\
0.86 \\
0.88 \\
0.85 \\
0.84\end{array}$ & & $\begin{array}{l}0.54 \\
0.59 \\
0.48 \\
0.63 \\
0.66 \\
0.46 \\
0.43 \\
0.47 \\
0.56\end{array}$ & $\begin{array}{l}0.79 \\
0.79 \\
0.80 \\
0.79 \\
0.78 \\
0.80 \\
0.81 \\
0.81 \\
0.79\end{array}$ \\
\hline \multirow[t]{2}{*}{$\begin{array}{l}\text { Hassles/burdens } \\
\text { subscale }\end{array}$} & & 0.84 & & & 0.79 & & \\
\hline & $\begin{array}{l}3 a \\
3 b \\
3 c \\
3 d \\
3 e \\
3 f \\
3 g \\
3 h\end{array}$ & & $\begin{array}{l}0.59 \\
0.73 \\
0.70 \\
0.48 \\
0.80 \\
0.56 \\
0.78 \\
0.004\end{array}$ & $\begin{array}{l}0.82 \\
0.80 \\
0.81 \\
0.83 \\
0.79 \\
0.82 \\
0.79 \\
0.88\end{array}$ & & $\begin{array}{l}0.51 \\
0.61 \\
0.57 \\
0.66 \\
0.70 \\
0.38 \\
0.74 \\
0.12\end{array}$ & $\begin{array}{l}0.76 \\
0.74 \\
0.75 \\
0.74 \\
0.73 \\
0.78 \\
0.73 \\
0.86\end{array}$ \\
\hline \multirow[t]{2}{*}{$\begin{array}{l}\text { Psychological } \\
\text { impact (positive) } \\
\text { subscale }\end{array}$} & & 0.65 & & & 0.79 & & \\
\hline & $\begin{array}{l}4 a \\
4 b \\
4 f \\
4 h \\
4 j\end{array}$ & & $\begin{array}{l}0.34 \\
0.54 \\
0.38 \\
0.48 \\
0.42\end{array}$ & $\begin{array}{l}0.63 \\
0.55 \\
0.65 \\
0.59 \\
0.59\end{array}$ & & $\begin{array}{l}0.60 \\
0.69 \\
0.49 \\
0.60 \\
0.55\end{array}$ & $\begin{array}{l}0.74 \\
0.72 \\
0.79 \\
0.75 \\
0.76\end{array}$ \\
\hline \multirow[t]{2}{*}{$\begin{array}{l}\text { Psychological } \\
\text { impact (negative) } \\
\text { subscale }\end{array}$} & & 0.64 & & & 0.56 & & \\
\hline & $\begin{array}{l}4 d \\
4 g \\
4 i\end{array}$ & & $\begin{array}{l}0.41 \\
0.55 \\
0.41\end{array}$ & $\begin{array}{l}0.62 \\
0.40 \\
0.59\end{array}$ & & $\begin{array}{l}0.39 \\
0.45 \\
0.30\end{array}$ & $\begin{array}{l}0.45 \\
0.33 \\
0.56\end{array}$ \\
\hline
\end{tabular}

Abbreviation: DASS, Duke Anticoagulation Satisfaction Scale.

\section{Discussion}

In our study, for the first time, the DASS was translated into the Maltese language and we administered this questionnaire to a group of patients on warfarin treatment for different clinical indications. We evaluated the reliability and the validity of the
Maltese translation in comparison to the psychometric properties of the DASS previously reported in the literature and to the original English version completed by a different group of patients in our study cohort. We found that the Maltese DASS has good reliability and an acceptable level of validity. 
Table 3 Response distribution for each DASS item of the Maltese translation and summary statistics

\begin{tabular}{|c|c|c|c|c|c|c|c|c|c|c|}
\hline \multirow{2}{*}{$\begin{array}{l}\text { DASS } \\
\text { item }\end{array}$} & \multicolumn{7}{|c|}{ Response category (\%) } & \multirow{2}{*}{$\begin{array}{l}\text { Mean (SD) in our } \\
\text { study (Maltese } \\
\text { version) }\end{array}$} & \multirow{2}{*}{$\begin{array}{l}\text { Mean (SD) in our } \\
\text { study (English } \\
\text { version) }\end{array}$} & \multirow{2}{*}{$\begin{array}{l}\text { Mean (SD) in the } \\
\text { study by Samsa et } \\
\text { al }^{10}\end{array}$} \\
\hline & $\mathbf{I}$ & 2 & 3 & 4 & 5 & 6 & 7 & & & \\
\hline la & 74.1 & 13.2 & 1.7 & 3.5 & 4.0 & 2.9 & 0.6 & $1.61(1.31)$ & $1.59(1.28)$ & $1.84(1.37)$ \\
\hline Ib & 75.9 & 12.1 & 3.5 & 2.9 & 1.7 & 3.5 & 0.6 & $1.55(1.25)$ & $1.50(1.12)$ & $1.36(0.99)$ \\
\hline Ic & 60.3 & 16.1 & 6.3 & 2.9 & 4.6 & 6.3 & 3.5 & $2.08(1.76)$ & $2.04(\mathrm{I} .5 \mathrm{I})$ & $1.69(1.36)$ \\
\hline Id & 76.4 & 12.6 & 2.3 & 2.3 & 1.7 & 3.5 & 1.2 & $1.55(1.30)$ & $1.46(1.14)$ & $1.84(1.78)$ \\
\hline le & 72.4 & 12.6 & 3.5 & 5.8 & 1.2 & 3.5 & 1.2 & $1.66(1.35)$ & $1.62(1.19)$ & $1.88(1.31)$ \\
\hline $2 \mathrm{a}$ & 39.1 & 24.7 & 13.2 & 9.8 & 8.1 & 4.6 & 0.6 & $2.39(1.54)$ & $2.10(1.35)$ & $2.60(1.66)$ \\
\hline $2 b$ & 70.1 & 13.2 & 2.3 & 4.6 & 2.3 & 4.6 & 2.9 & I.8I (1.60) & 2.14 (1.59) & $1.97(1.89)$ \\
\hline $2 c$ & 46.6 & 19.5 & 10.9 & 4.0 & 9.2 & 5.8 & 4.0 & $2.43(1.82)$ & 2.71 (1.96) & $3.02(2.12)$ \\
\hline $2 d$ & 55.2 & 20.1 & 8.1 & 8.1 & 2.3 & 4.0 & 2.3 & $2.03(1.55)$ & $\mathrm{I} .86(\mathrm{I} .2 \mathrm{I})$ & $2.20(1.43)$ \\
\hline $3 a$ & 63.2 & 17.8 & 5.8 & 5.2 & 2.3 & 4.0 & 1.7 & I.84 (I.47) & $1.80(1.19)$ & I.78 (I.22) \\
\hline $3 b$ & 46.6 & 19.0 & 9.8 & 11.5 & 4.6 & 5.8 & 2.9 & $2.37(1.72)$ & 2.15 (1.49) & $2.09(1.25)$ \\
\hline $3 c$ & 62.1 & 20.1 & 5.2 & 6.3 & 3.5 & 2.9 & 0.0 & 1.78 (I.29) & $1.66(1.16)$ & 1.65 (1.09) \\
\hline $3 d$ & 74.1 & 10.3 & 5.2 & 2.9 & 4.0 & 3.5 & 0.0 & $1.63(1.30)$ & $1.78(1.08)$ & $1.76(0.97)$ \\
\hline $3 e$ & 57.5 & 16.1 & 7.5 & 6.3 & 5.2 & 6.3 & 1.2 & $2.09(1.64)$ & $1.85(1.35)$ & $1.76(1.24)$ \\
\hline $3 f$ & 69.0 & 14.4 & 7.5 & 3.5 & 4.6 & 0.6 & 0.6 & $1.64(1.20)$ & $1.33(0.90)$ & $1.37(0.90)$ \\
\hline $3 g$ & 52.3 & 23.0 & 5.8 & 7.5 & 5.2 & 5.2 & 1.2 & $2.10(1.57)$ & $1.94(1.19)$ & I.8I (I.I7) \\
\hline $3 \mathrm{~h}$ & 7.5 & 52.3 & 23.0 & 5.2 & 4.0 & 4.6 & 3.5 & 2.74 (I.39) & 2.77 (1.98) & $2.90(2.19)$ \\
\hline $4 a$ & 4.0 & 31.6 & 30.5 & 16.7 & 4.6 & 10.3 & 2.3 & $3.26(1.44)$ & $2.54(1.50)$ & $2.32(1.67)$ \\
\hline $4 b$ & 4.0 & 40.2 & 28.2 & 17.2 & 4.0 & 4.6 & 1.7 & $2.98(1.26)$ & $2.64(1.46)$ & $2.78(1.66)$ \\
\hline $4 d$ & 20.7 & 15.5 & 10.9 & 18.4 & 14.9 & 14.9 & 4.6 & 3.55 (1.89) & 2.87 (I.77) & $2.55(1.64)$ \\
\hline $4 f$ & 7.5 & 19.0 & 12.1 & 10.3 & 8.6 & 14.9 & 27.6 & $4.49(2.12)$ & 4.01 (2.0I) & $4.15(2.08)$ \\
\hline $4 g$ & 58.7 & 14.9 & 6.9 & 9.2 & 4.6 & 5.2 & 0.6 & $2.04(1.56)$ & $2.24(1.48)$ & $2.00(1.34)$ \\
\hline $4 \mathrm{~h}$ & 11.5 & 59.2 & 18.4 & 6.9 & 1.2 & 1.2 & 1.7 & $2.37(1.08)$ & $2.4 \mathrm{I}(1.35)$ & $2.55(1.60)$ \\
\hline $4 i$ & 55.8 & 20.1 & 6.3 & 10.9 & 3.5 & 2.9 & 0.6 & $1.97(I .4 I)$ & $1.68(1.22)$ & $1.75(1.23)$ \\
\hline $4 j$ & 10.9 & 45.4 & 24.1 & 11.5 & 2.3 & 2.9 & 2.9 & $2.69(1.32)$ & $2.91(1.93)$ & $2.42(1.73)$ \\
\hline
\end{tabular}

Note: Numbers in bold in the response category section indicate significant floor or ceiling effect. Abbreviation: DASS, Duke Anticoagulation Satisfaction Scale.

The internal consistency was very good, with Cronbach's alpha coefficients for the overall DASS score and the subscales limitations and hassles/burdens above 0.80 . The Cronbach's alpha coefficients were slightly below the acceptable cut-off for the positive and negative psychological impact subscales $(0.65$ and 0.64 , respectively). However, lower coefficients were reported in another study evaluating the BrazilianPortuguese version of the DASS $(0.67$ and 0.38 , respectively $)^{13}$ and in the English version in our study cohort ( 0.79 and 0.56 , respectively). The low number of items included in these two subscales (5 questions in the positive impact and 3 questions in the negative impact) might be contributing to this finding.

Test-retest reliability (intra-language correlation) of the DASS in our cohort was very good with an ICC of 0.73 for the Maltese version and 0.85 for the English version, which are above the desirable cut-off and similar to values reported in the literature. ${ }^{10,32}$ Given the peculiarity of the Maltese population with high percentage of bilingual subjects, ${ }^{37}$ we were also able to assess the cross-language correlation. Despite the rigorous process of translation, the ICC for the cross-language correlation was lower than the ICC for the intra-language correlation. However, this finding has been previously reported by several authors ${ }^{27,38}$ and different solutions have been proposed. Wood et al hypothesized that it could be due to score unreliability and suggested to adjust the cross-language correlation by the intra-language correlation, ${ }^{27}$ while Chung et al hypothesized that it could be due to poor bilingual proficiency and performed a sub-analysis of subjects with higher level of education. ${ }^{38}$ In agreement with the study by Wood et al, ${ }^{27}$ we obtained better crosslanguage correlation when applying the suggested adjustment. In our study, the number of retested patients with higher level of education was too low to perform a specific sub-analysis. However, when we analyzed separately the English-Maltese and Maltese-English test-retest, we 


\begin{tabular}{|c|c|c|}
\hline \multirow{3}{*}{ 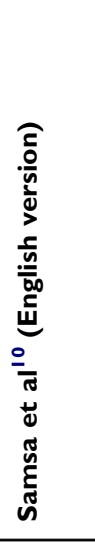 } & 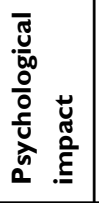 & 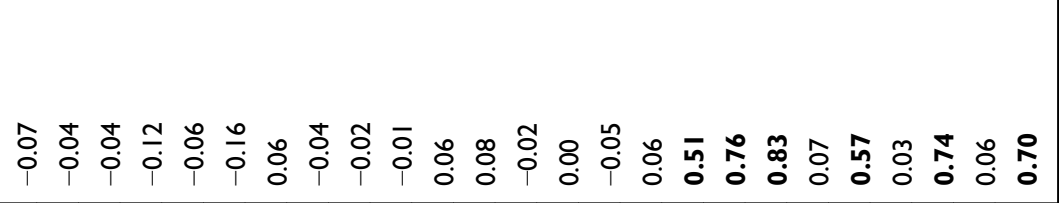 \\
\hline & 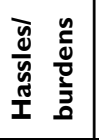 & 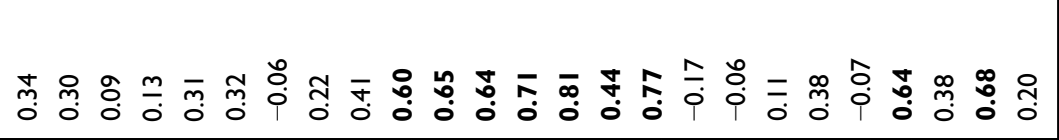 \\
\hline & 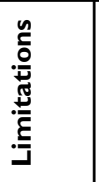 & 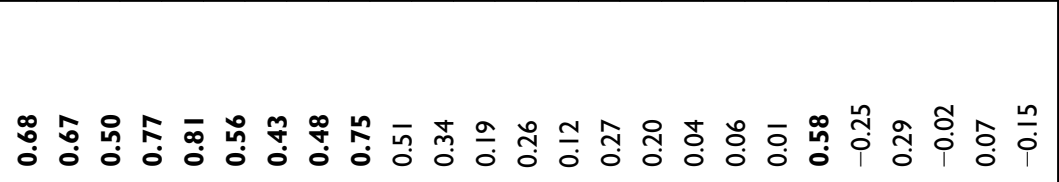 \\
\hline \multirow{3}{*}{ 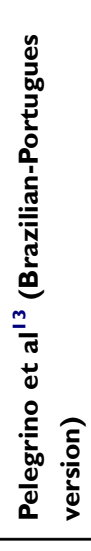 } & 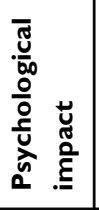 & 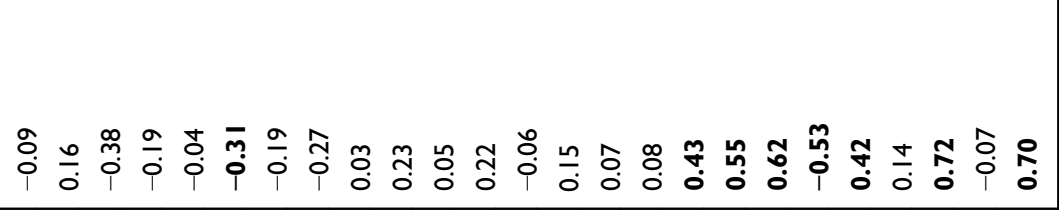 \\
\hline & 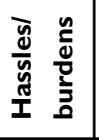 & 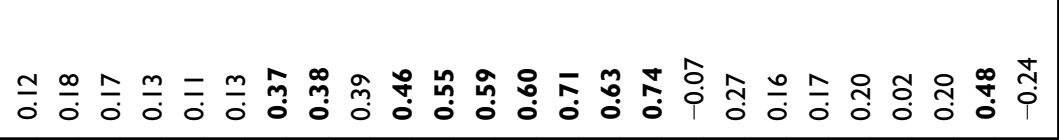 \\
\hline & . & 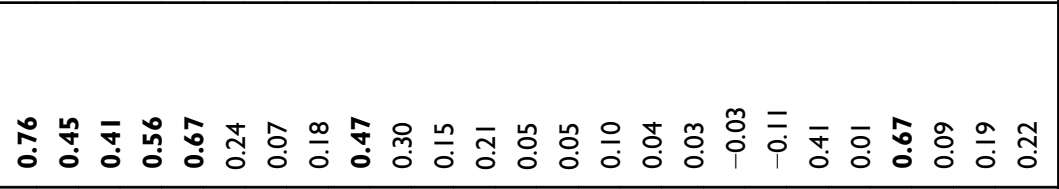 \\
\hline \multirow{3}{*}{ 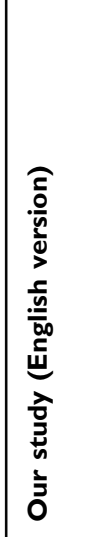 } & 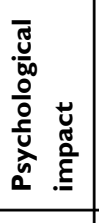 & 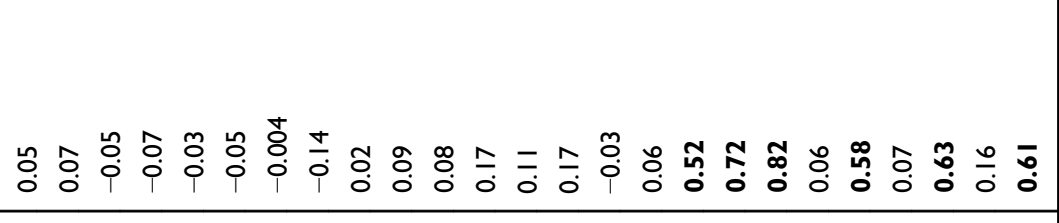 \\
\hline & 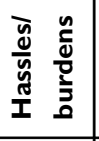 & 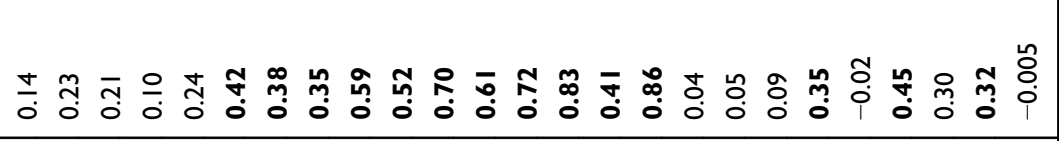 \\
\hline & 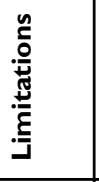 & 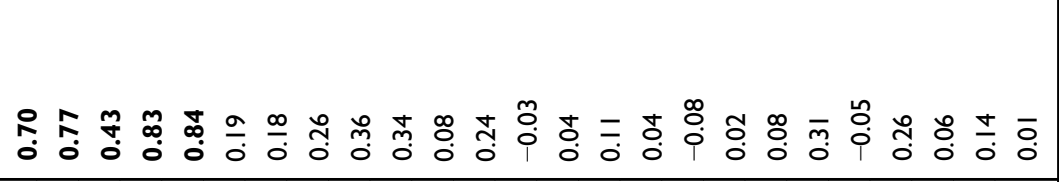 \\
\hline \multirow{3}{*}{ 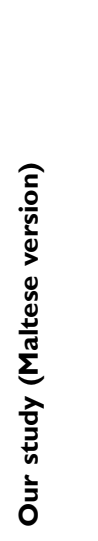 } & 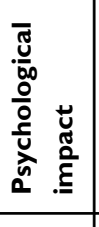 & 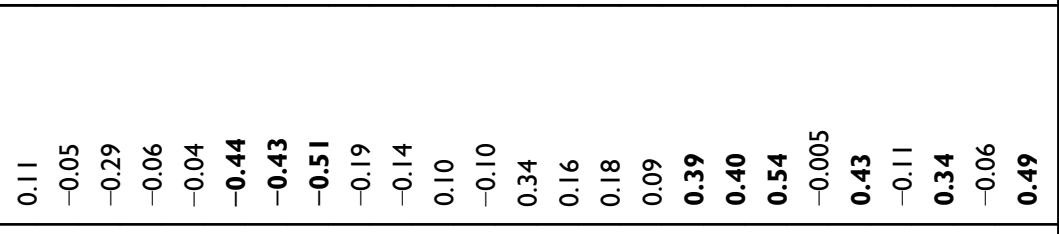 \\
\hline & 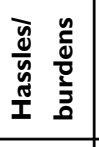 & 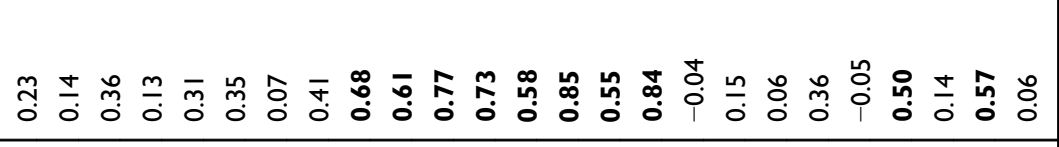 \\
\hline & 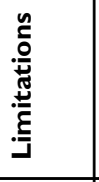 & 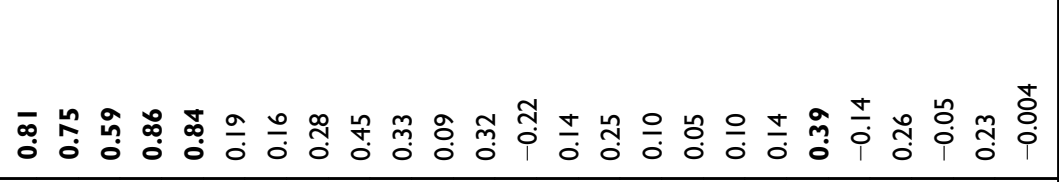 \\
\hline & $\underline{\underline{E}}$ & 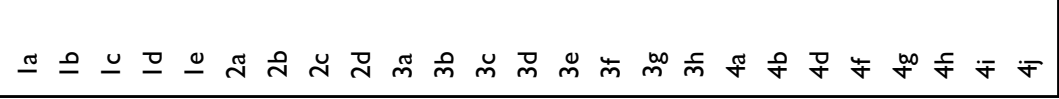 \\
\hline
\end{tabular}


Table 5 Correlation between satisfaction and sociodemographic or clinical characteristics

\begin{tabular}{|l|l|l|}
\hline Variable & $\begin{array}{l}\text { Correlation coefficient for DASS } \\
\text { total score for the Maltese version } \\
(\boldsymbol{P} \text {-value) }\end{array}$ & $\begin{array}{l}\text { Correlation coefficient for DASS } \\
\text { total score for the English version } \\
(\boldsymbol{P} \text {-value })\end{array}$ \\
\hline Increasing age & $-0.12(0.12)$ & $-0.25(0.002)$ \\
Sex: male & $-0.15(0.05)$ & $-0.22(0.004)$ \\
Living situation: living alone & $-0.02(0.72)$ & $0.06(0.45)$ \\
Level of education: primary school only & $-0.05(0.54)$ & $0.01(0.86)$ \\
Employment status: full- or part-time paid employment & $0.09(0.37)$ & $0.17(0.04)$ \\
Clinical indication to anticoagulation: atrial fibrillation & $-0.09(0.23)$ & $-0.08(0.30)$ \\
Anticoagulant treatment duration: $>5$ years & $-0.18(0.02)$ & $-0.05(0.55)$ \\
INR in range at enrollment & $-0.06(0.41)$ & $-0.01(0.94)$ \\
High TTR $(\geq 70 \%)$ in the previous year & $-0.01(0.86)$ & $-0.05(0.53)$ \\
Any hospitalization in the previous year & $0.17(0.03)$ & $0.14(0.09)$ \\
Self-reported history of any bleeding on warfarin & $0.20(0.01)$ & $0.20(0.01)$ \\
\hline
\end{tabular}

Note: Since lower DASS total scores represent greater satisfaction, a negative correlation means greater satisfaction.

Abbreviations: INR, international normalized ratio; TTR, time within therapeutic range; DASS, Duke Anticoagulation Satisfaction Scale.

observed poor results only in the latter. This finding suggests that those patients who initially chose to complete the Maltese version of the questionnaire were probably less confident in English, in line with the hypothesis by Chung et al. ${ }^{38}$

While ceiling effect was found only in one question, a significant floor effect was observed in both the Maltese and the English versions in our study, as well as in the original publication of the DASS, ${ }^{10}$ suggesting that it is more likely to be an intrinsic characteristic of the questionnaire itself rather than a weakness of the Maltese translation.

Results of the confirmatory factor analysis were not satisfactory: RMSEA and SRMR were slightly above the acceptable limit; while GFI, AGFI and CFI were significantly below the acceptable cut-off. However, the fit parameters were not reported in previous studies, making it impossible to compare these results. Therefore, we performed an additional exploratory factor analysis which showed that the factors load on the three subscales was similar to previous publications. ${ }^{10,13}$

Regarding construct validity, a significant positive correlation was found between the overall DASS score and its subscales, in line with the fact that the DASS total score is the sum of its three subscales (limitations, hassles and burdens, and psychological impact).

For the known-group validity, both versions of the DASS in our study correlated with sex and history of bleeding. The Maltese version correlated also with anticoagulant treatment duration and hospitalization in the previous year, while the English version correlated also with age and employment status. Differences in the study population between patients who completed the Maltese and the English version of the DASS might have contributed to these slightly different results. Similarly, previous studies reported that younger age ${ }^{10,13}$ and working status ${ }^{12,32}$ were associated with lower satisfaction, suggesting that the burden of anticoagulant therapy and INR monitoring is greater for young working people, compared to older retirees. In addition, hospitalization for bleeding correlated with lower satisfaction in the studies by Samsa et $\mathrm{al}^{10}$ and Radaideh et al. ${ }^{32}$ Although in our study we used two different definitions (hospitalization in the previous year and self-reported history of any bleeding), they showed the same correlation with the DASS total score. Finally, higher treatment satisfaction was reported by those patients on VKA treatment for more than 5 years.

Anticoagulant therapy is the mainstay for the treatment of VTE and for stroke prevention in patients with AF or mechanical heart valves. In Malta around $1 \%$ of the population is anticoagulated, ${ }^{39}$ corresponding to approximately 4000 people. However, to the best of our knowledge, there was no specific quality of life instrument for anticoagulated patients that had been validated in the Maltese language. Assessing the QoL is important in order to improve the quality of care for anticoagulated patients. It has been shown that satisfaction correlates with adherence and INR control ${ }^{40,41}$ and that, in turn, the TTR correlates with thromboembolic and bleeding complications. ${ }^{42}$ By identifying limitations and hassles associated with VKA treatment, health care professionals can provide specific educational interventions to improve the burden associated with this treatment. Furthermore, they can also 
reinforce the positive aspects which are salient for each patient. In our research project, we decided to translate the DASS and the PACT-Q, because they are both psychometric questionnaires that can be specifically used to assess the quality of life of anticoagulated patients. Therefore, they were administered at the same time to the same patients' population (results of the validation of the PACT-Q2 are reported elsewhere). ${ }^{20}$ The PACT-Q2 is shorter (20 questions to be answered on a 5-point Likert scale), however the items of the two dimensions "convenience" and "treatment satisfaction" have to be scored separately. Conversely, the DASS is slightly longer (25 questions to be answered on a 7-point scale) but has the advantage that can provide one overall final score. The DASS was originally developed in the English ${ }^{10}$ and, so far, it has been translated and validated in Greek, ${ }^{12}$ BrazilianPortuguese, ${ }^{13}$ Malay $^{32}$ and Turkish. ${ }^{33}$ In our study, it was translated in Maltese and tested in 157 patients who completed the Maltese version and in 174 patients who completed the English version. The availability of a large number of patients enrolled from the same setting in a short time frame, who completed the questionnaire in two different languages is a peculiarity of our study. In fact, both English and Maltese are official languages in Malta and it has been estimated that more than two thirds of the population are bilingual, ${ }^{37}$ although there is the prevalence of one language over the other in certain areas (e.g., Maltese predominates as spoken language, while English is mainly used in written communications). ${ }^{23}$ In our study patients were enrolled from different locations around the Maltese island, therefore our sample is likely to be generalizable to the overall anticoagulated Maltese population. Furthermore, although we included only patients on VKA, at the time of enrollment the overwhelming majority of anticoagulated patients in Malta were on warfarin, since the novel direct oral anticoagulants were not centrally funded.

The main strengths of our study are the completeness of data (no missing answers) and the rigorous analysis to validate the Maltese version of the DASS. Furthermore, a group of patients in our study cohort completed the original English version of the DASS, therefore allowing a comparison of the psychometric properties of the two versions in the same population.

However, our study has also some limitations which need to be acknowledged. First, only patients on VKA treatment were enrolled; therefore, our results might not be generalizable to patients treated with other oral anticoagulants. Second, the number of patients included in the test-retest was smaller than the generally recommended size by Terwee et $\mathrm{al}^{29}$ for the calculation of the ICC.

\section{Conclusion}

The Maltese version of the DASS, administered to patients receiving oral anticoagulation with VKA, showed good reliability and an acceptable level of validity. These findings were comparable to the original English version. The results of our study suggest that the Maltese DASS is a valid and reliable instrument to assess the level of satisfaction of Maltesespeaking anticoagulated patients. It can be therefore used by health care professionals working in the setting of anticoagulation clinics or in future research studies assessing patients' satisfaction and barriers to anticoagulant treatment.

\section{Acknowledgment}

We would like to thank all the patients who completed the questionnaires and the staff of the Anticoagulation Clinics at Cospicua, Floriana, Mosta, Qormi, Rabat Health Centres and at Mater Dei Hospital for their help in patient recruitment. We would also like to thank Dr Elayne Azzopardi (Speech and Language Pathologist, College of Medicine, Swansea University, Swansea, UK) and Dr George Farrugia (Senior Lecturer, Department of Maltese, Faculty of Arts, University of Malta, Msida, Malta) for their contribution to the Maltese translation of the DASS, and Dr Lorenza Bertù (Biostatistician, Department of Medicine and Surgery, University of Insubria, Varese, Italy) for her assistance in statistical analysis. This study was supported by a research grant from the University of Malta.

\section{Disclosure}

Nicoletta Riva reports grants from University of Malta, during the conduct of the study. Walter Ageno reports grants and personal fees from Bayer, and BMS/Pfizer; personal fees from Daiichi Sankyo, Boehringer Ingelheim, Portola, Sanofi, and Aspen, outside the submitted work. The authors report no other conflicts of interest in this work.

\section{References}

1. Casais P, Meschengieser SS, Sanchez-Luceros A, Lazzari MA. Patients' perceptions regarding oral anticoagulation therapy and its effect on quality of life. Curr Med Res Opin. 2005;21(7):1085-1090. doi:10.1185/030079905X50624

2. Borg Xuereb C, Shaw RL, Lane DA. Patients' and physicians' experiences of atrial fibrillation consultations and anticoagulation decisionmaking: a multi-perspective IPA design. Psychol Health. 2016;31 (4):436-455. doi:10.1080/08870446.2015.1116534

3. Wild D, Murray M, Shakespeare A, Reaney M, von Maltzahn R. Patient-reported treatment satisfaction measures for long-term anticoagulant therapy. Expert Rev Pharmacoecon Outcomes Res. 2008;8 (3):291-299. doi:10.1586/14737167.8.3.291 
4. Ageno W, Gallus AS, Wittkowsky A, et al. Oral anticoagulant therapy: antithrombotic therapy and prevention of thrombosis, 9th ed: American College of Chest Physicians evidence-based clinical practice guidelines. Chest. 2012;141(2Suppl):e44S-e88S. doi:10.1378/chest.11-2292

5. Ware JE Jr., Sherbourne CD, The MOS. 36-item short-form health survey (SF-36). I. Conceptual framework and item selection. Med Care. 1992;30(6):473-483.

6. Ware JE Jr., Kosinski M, Keller SD. A 12-item short-form health survey: construction of scales and preliminary tests of reliability and validity. Med Care. 1996;34(3):220-233.

7. Kanazawa I, Takeno A, Tanaka KI, Yamane Y, Sugimoto T. Osteoporosis and vertebral fracture are associated with deterioration of activities of daily living and quality of life in patients with type 2 diabetes mellitus. J Bone Miner Metab. 2018. [Epub ahead of print] PubMed PMID: 30191456. doi:10.1007/s00774-018-0948-6

8. Matcham F, Scott IC, Rayner L, et al. The impact of rheumatoid arthritis on quality-of-life assessed using the SF-36: a systematic review and meta-analysis. Semin Arthritis Rheum. 2014;44(2):123130. doi:10.1016/j.semarthrit.2014.05.001

9. Arian M, Mirmohammadkhani M, Ghorbani R, Soleimani M. Healthrelated quality of life (HRQoL) in beta-thalassemia major ( $\beta$-TM) patients assessed by 36-item short form health survey (SF-36): a meta-analysis. Qual Life Res. 2019;28(2):321-334. doi:10.1007/ s11136-018-1986-1

10. Samsa G, Matchar DB, Dolor RJ, et al. A new instrument for measuring anticoagulation-related quality of life: development and preliminary validation. Health Qual Life Outcomes. 2004;2:22. doi:10.1186/1477-7525-2-22

11. Prins MH, Marrel A, Carita P, et al. Multinational development of a questionnaire assessing patient satisfaction with anticoagulant treatment: the 'Perception of Anticoagulant Treatment Questionnaire' (PACT-Q). Health Qual Life Outcomes. 2009;7:9. doi:10.1186/1477-7525-7-9

12. Gafou A, Maragos K, Bellia M, Digenopoulou-Andrioti E, Theodosiadis G. Instruments for measuring anticoagulation-related quality of life: modification, and preliminary validation. Haema. 2007;10(2-3):129-141.

13. Pelegrino FM, Dantas RA, Corbi IS, Da Silva Carvalho AR, Schmidt A, Pazin Filho A. Cross-cultural adaptation and psychometric properties of the Brazilian-Portuguese version of the Duke Anticoagulation Satisfaction Scale. J Clin Nurs. 2012;21(17-18):2509-2517. doi:10.1111/j.1365-2702.2011.03869.x

14. Matchar DB, Jacobson A, Dolor R, et al. Effect of home testing of international normalized ratio on clinical events. $N$ Engl J Med. 2010;363(17):1608-1620. doi:10.1056/NEJMoa1002617

15. Hasan SS, Teh KM, Ahmed SI, Chong DW, Ong HC, Naina B. Quality of life (QoL) and International Normalized Ratio (INR) control of patients attending anticoagulation clinics. Public Health. 2015;129(7):954-962. doi:10.1016/j.puhe.2015.05.014

16. Prins $\mathrm{MH}$, Guillemin I, Gilet $\mathrm{H}$, et al. Scoring and psychometric validation of the Perception of Anticoagulant Treatment Questionnaire (PACT-Q). Health Qual Life Outcomes. 2009;7:30. doi:10.1186/1477-7525-7-30

17. Mohamed S, Razak TA, Hashim R. Translation, validation and psychometric properties of Bahasa Malaysia version of the Perception of Anticoagulant Therapy Questionnaire (PACTQ). Asian J Biomed Pharm Sci. 2015;5(48):18-22. doi:10.15272/ajbps.v5i48.730

18. Agnelli G, Gitt AK, Bauersachs R, et al. The management of acute venous thromboembolism in clinical practice - study rationale and protocol of the European PREFER in VTE Registry. Thromb J. 2015;13:41. doi:10.1186/s12959-015-0071-z

19. De Caterina R, Brüggenjürgen B, Darius H, et al. Quality of life and patient satisfaction in patients with atrial fibrillation on stable vitamin $\mathrm{K}$ antagonist treatment or switched to a non-vitamin $\mathrm{K}$ antagonist oral anticoagulant during a 1-year follow-up: a PREFER in AF registry substudy. Arch Cardiovasc Dis. 2018;111(2):74-84. doi:10.1016/j. acvd.2017.04.007
20. Riva N, Borg Xuereb C, Makris M, Ageno W, Gatt A. Reliability and validity of the Maltese version of the Perception of Anticoagulant Treatment Questionnaire (PACT-Q). Patient Prefer Adherence. 2019. In Press. doi:10.2147/PPA.S207498

21. Sousa VD, Rojjanasrirat W. Translation, adaptation and validation of instruments or scales for use in cross-cultural health care research: a clear and user-friendly guideline. J Eval Clin Pract. 2011;17(2):268274. doi:10.1111/j.1365-2753.2010.01434.x

22. Beaton DE, Bombardier C, Guillemin F, Ferraz MB. Guidelines for the process of cross-cultural adaptation of self-report measures. Spine (Phila Pa 1976). 2000;25(24):3186-3191. doi:10.1097/00007632-20001215000014

23. Vella A. Languages and language varieties in Malta. Int J Biling Educ Biling. 2013;16(5):532-552. doi:10.1080/13670050.2012. 716812

24. Webb NM, Shavelson RJ, Haertel EH. Reliability coefficients and generalizability theory. In: Rao CR, Sinharay S, editors. Handbook of Statistics: Vol 26 Psychometrics. Holland: Elsevier; 2006:81124.

25. Cronbach LJ. Coefficient alpha and the internal structure of tests. Psychometrika. 1951;22(3):297-334. doi:10.1007/BF02310555

26. Cicchetti DV. Guidelines, criteria, and rules of thumb for evaluating normed and standardized assessment instruments in psychology. Psychol Assess. 1994;6(4):284-290. doi:10.1037/1040-3590. 6.4.284

27. Wood D, Qiu L, Lu J, Lin H, Tov W. Adjusting Bilingual ratings by retest reliability improves estimation of translation quality. $J$ Cross Cult Psychol. 2018;49(9):1325-1339. doi:10.1177/ 0022022118789773

28. McCrae RR, Yik MS, Trapnell PD, Bond MH, Paulhus DL. Interpreting personality profiles across cultures: bilingual, acculturation, and peer rating studies of Chinese undergraduates. J Pers Soc Psychol. 1998;74(4):1041-1055.

29. Terwee CB, Bot SD, de Boer MR, et al. Quality criteria were proposed for measurement properties of health status questionnaires. $J$ Clin Epidemiol. 2007;60(1):34-42. doi:10.1016/j.jclinepi.2006. 03.012

30. McDonald RP, Ho MH. Principles and practice in reporting structural equation analyses. Psychol Methods. 2002;7(1):64-82.

31. Streiner DL, Norman GR, Cairney J. Health Measurement Scales: A Practical Guide to Their Development and Use. Oxford: Oxford University Press; 2015.

32. Radaideh KM, Matalqah LM. Health-related quality of life among atrial fibrillation patients using warfarin therapy. Epidemiol Biostatistics Public Health. 2018;15(1):e12763.1-8.

33. Yildiz E, Dayapoglu N. The satisfaction levels of patients using anticoagulants. Int J Caring Sci. 2017;10(1):568-574.

34. Rosendaal FR, Cannegieter SC, van der Meer FJ, Briët E. A method to determine the optimal intensity of oral anticoagulant therapy. Thromb Haemost. 1993;69:236-239.

35. Frey PM, Méan M, Limacher A, et al. Quality of life after pulmonary embolism: prospective validation of the German version of the PEmb-QoL questionnaire. Thromb Res. 2015;135(6):1087-1092. doi:10.1016/j.thromres.2015.03.031

36. Rochat M, Méan M, Limacher A, et al. Quality of life after pulmonary embolism: validation of the French version of the PEmb-QoL questionnaire. Health Qual Life Outcomes. 2014;12:174. doi:10.1186/s12955-014-0174-4

37. National Statistics Office, Malta. Census of population and housing 2011: final report. January 31, 2014. Available from: https://nso.gov.mt/en/pub licatons/Publications_by_Unit/Documents/01_Methodology_and_ Research/Census2011_FinalReport.pdf. Accessed December 16, 2018.

38. Chung JJ, Weed NC, Han K. Evaluating cross-cultural equivalence of the Korean MMPI-2 via bilingual test-retest. Int $J$ Intercultural Relat. 2006;30:531-543. doi:10.1016/j.ijintrel. 2005.08.009 
39. Zammit G, Farrugia R, Barbara $\mathrm{C}$, et al. Anticoagulation services in Malta - an economic study comparing a central laboratory model vs. a point-of-care approach. Int J Lab Hematol. 2011;33(3):e7-e8. doi:10.1111/j.1751-553X.2010.01279.x

40. Balkhi B, Al-Rasheedi M, Elbur AI, Alghamadi A. Association between satisfaction with and adherence to warfarin therapy on the control of international normalized ratio: a hospital-based study in Saudi Arabia. Saudi Pharm J. 2018;26(1):145-149. doi:10.1016/j.jsps.2017.11.010
41. Bartoli-Abdou JK, Patel JP, Xie R, et al. Associations between illness beliefs, medication beliefs, anticoagulation-related quality of life, and INR control: insights from the switching study. Res Pract Thromb Haemost. 2018;2(3):497-507. doi:10.1002/rth2.12116

42. Pokorney SD, Simon DN, Thomas L, et al. Patients' time in therapeutic range on warfarin among US patients with atrial fibrillation: results from ORBIT-AF registry. Am Heart J. 2015;170(1):141-8, 8. e1. doi:10.1016/j.ahj.2015.03.017

\section{Publish your work in this journal}

Psychology Research and Behavior Management is an international, peer-reviewed, open access journal focusing on the science of psychology and its application in behavior management to develop improved outcomes in the clinical, educational, sports and business arenas. Specific topics covered in the journal include: Neuroscience, memory and decision making; Behavior modification and management; Clinical applications; Business and sports performance management; Social and developmental studies; Animal studies. The manuscript management system is completely online and includes a very quick and fair peer-review system, which is all easy to use. Visit http://www. dovepress.com/testimonials.php to read real quotes from published authors. 